\title{
Strengthening Performance for Teachers in Early Childhood Education with Heutagogy on the Utilization of Digital Learning Media and Sources
}

\author{
Henry Praherdhiono \\ Technology Education \\ State University of Malang \\ henry.praherdhiono.fip@um.ac.id
}

\author{
Eka Pramono Adi \\ Technology Education \\ State University of Malang \\ eka.pramono.fip@um.ac.id
}

\author{
Yulias Prihatmoko \\ Technology Education \\ State University of Malang \\ yulias.prihatmoko.fip@um.ac.id
}

\begin{abstract}
Digital learning sources have been able to construct individuals and society. Even far in the future, the culture will experience change because the digital environment evolves to facilitate adaptation. The condition of prospective teachers who have experienced the ease of use of gadgets to access the required content. The development of digital sources is no longer a trend, but has been implemented in the context of efficiency and effectiveness. So the development of digital learning resources to serve complex and fast learning needs.
\end{abstract}

Keywords-digital learning resources, heutagogy, early childhood education, learning media

\section{INTRODUCTION}

Learning for prospective teachers, early childhood education requires a heutagogy approach. This approach has an important role in empowering teachers in a comprehensive manner. The heutagogy approach is not a new approach to learning. Various notes suggest that the heutagogy approach was used around 2000 [1]. The heutagogy approach to education for children of age is not the best idea to be implemented in the learning of prospective teacher of early childhood education. However, various discussions conducted by lecturers at the beginning of the lecture, there was a general dissatisfaction with the implementation of education. Heutagogy approach is intended to foster the ability of prospective teachers in expanding the limits of knowledge, attitudes, and skills. During this time, pedagogy is only oriented to teachers alone. Learning requires development towards more aspirational.

Scientific development in early childhood education has not become a foothold for prospective teachers. They even still use a traditional approach. Early childhood education and interventions that divide skills development into three areas: 1) cognitive skills, 2) school readiness, and 3) social and emotional development [2]. So that the development of cognitive skills, and especially on IQ becomes an indicator of success for teacher activity. Although a high IQ is clearly not a perfect predictor after they mature, this is positively correlated with children's success in many fields.

However, while we know that the IQ of developing children can be disrupted through deprivation, it is not clear that it can be increased through extra stimulation in normal children. This deprivation is the domain of prospective teachers. The prospective teacher's learning experience to study independently deprivation is an example of the case of the importance of heutagogy in learning.

The heutagogy approach is also needed to strengthen the capabilities of prospective teachers. Various studies assume that teachers do learning only refers to deficiencies in the skills and cognitive of children. But when asked to mention the most important determinants of learning readiness, the attributes most frequently cited by teachers are: 1) how to stay physically fit, rested, and well nourished; 2) able to communicate needs, desires and thoughts orally; 3) enthusiasm and curiosity in approaching activities are new, and 4) know how to sit still and pay attention [3].

Some prospective teachers, early childhood, are not yet aware of students' intellectual achievement. Teachers do not think that it is important to incorporate knowledge into children in knowing the alphabet with fast and efficient techniques [4]. The impact of the teacher's ability is that the community becomes skeptical because the teacher cannot find the minimum knowledge for his knowledge as a form of self-serving.

Teachers prefer to maintain traditional views, namely learning that is fun to teach children, more verbal, and behave cheerfully so that children are not sullen, quiet, and restless. Empowering prospective teachers, early childhood education, as stated [5] explains the importance of strengthening cognitive, social and emotional skills for prospective teachers themselves. Many evidence regarding the issue of independent learning, behavior, skills development such as self-control may at least be a reference for prospective teacher capabilities [6].

\section{PREPARING OPEN MEDIA AND LEARNING RESOURCES}

Media in educational technology requires continuous innovation. People who work with educational technology have a passion for innovation, and always carry out their innovations into various digital learning resources in their learning environments [7]. When the providers of education and learning have been on the face to implement the media, the institutions of education providers no longer need to motivate people to use it. 


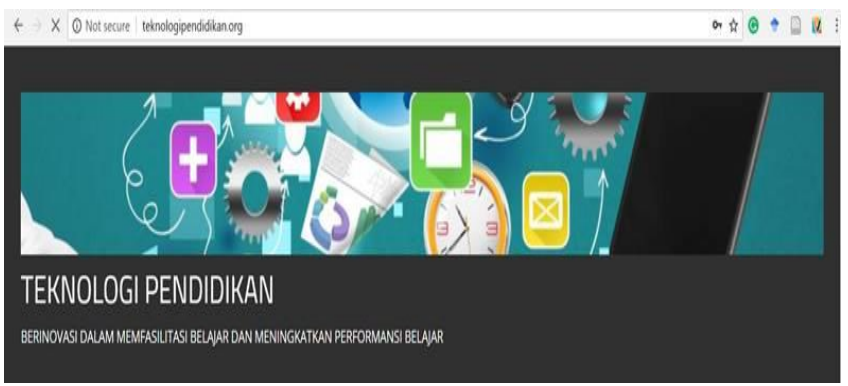

Fig. 1. Development of Learning Resources for Technology (education.org)

The challenge of education providers in the future is precisely how to motivate people to use media effectively and efficiently in a comfortable learning environment [8]. The media will not only change the way prospective teachers want to learn but will also change the way educators and teachers think about learning and learning. The Educational Technology State University of Malang, in addition to LMS which is held at the university level, also has a MOOC which is carried out in education technology.org. The activity is intended to provide enrichment of learning resources in the learning era in the digital user community.

\section{PREPARING TEACHERS TO FACE THE GLOBAL LEARNING CULTURE}

New technology a right to create a new culture. Media and technology are full of creative potential and at the same time also have the potential for abuse and even "abuse" [9]. Some of the facts experienced by educational institutions are that the presence of technology in learning does not always benefit the majority of prospective teachers and always improves learning[10]. Only with media and technology exposure for potential teacher candidates is not enough. There is no guarantee that learning will proceed well only with digital learning resources. Social media technology (figure 2) is often involved in learning

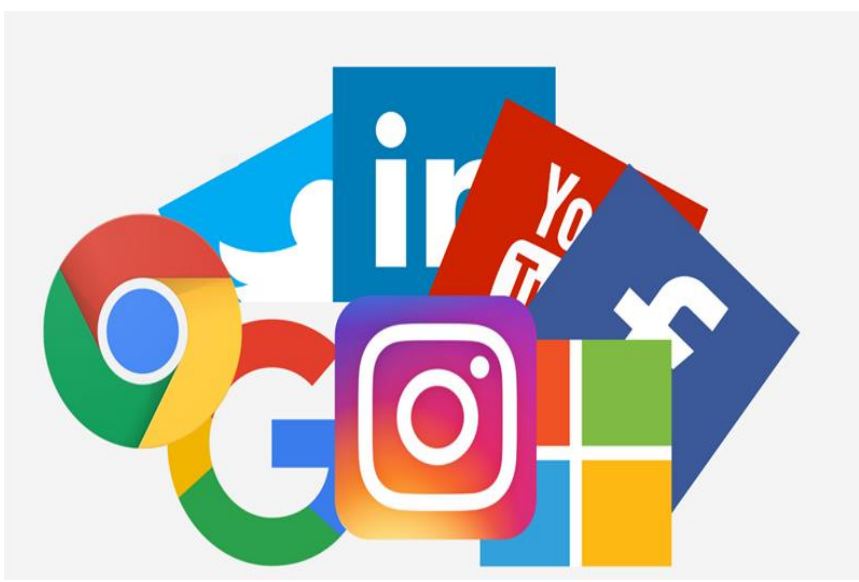

Fig. 2. Education through Social Media [11]

Digital learning resources should not only be used in additional sessions in the learning and learning process. Users of digital learning resources must be able to explore the strengths and potential of digital learning resources so that the learning and learning processes become very valuable [12]. The use of digital learning resources in digital form must be a major factor in the quality of learning in the present era [13]. Besides that, the most important thing is the use of media and learning technology effectively and efficiently. Learning resources that are broadcast through digital learning resources are challenges and opportunities for educators and teachers. If effectiveness and efficiency are ignored, then the fundamental laws that apply to the application of media and technology to learning and learning namely media and learning technology do not reduce costs or increase outcomes for anyone [14].

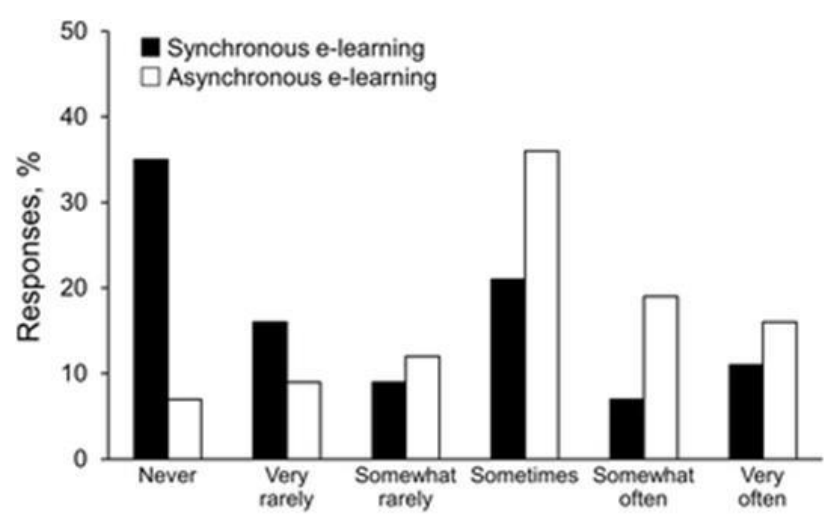

Fig. 3. Use of e-learning [15]

\section{INFLUENTIAL ASPECTS OF DIGITAL LEARNING RESOURCES}

Learning activities always refer to learning resources. The statement of learning resources as needs is not a debate. Frequent debates are 1) effective digital learning resources for learning [14], and 2) how learning resources can be designed, developed, used, reused, and managed [16]. The shape exploration of digital media for teaching and learning. Specifically, the need for digital media as a learning resource is :

- Development guide of digital learning resources for teaching and learning.

- Practical recommendations for the use of digital learning resources in educational activities.

- A useful reference for professors to identify, use and reuse of digital learning resources for learning in their teaching.

- The concept of digital learning resources for their own teaching.

- References for digital media publishers and educational resource designers because they provide unique perspectives and approaches to conceptualization, design, development, and dissemination of digital learning resources for learning and learning.

- Problem-learning issues surrounding the design, development, and use of digital learning resources for teaching and learning

Development of digital learning resources always intersects with the culture of global learning behavior [15]. The Global culture that is always influenced by strong cultures from developed countries such as countries in the Americas such as the United States and Canada, countries in 
continental Europe such as Britain and Germany, countries in Asia such as Japan and China. Tercampurya the culture experienced by the user's number of digital learning characterized by the use of global learning resources shown in figure 3. Literature sources, connections with lecturers, access to address URLs, broadcasts are mostly global cultural products [17].

Global learning behavior is learning behavior that is no longer limited by religious tribal, tribal and scientific barriers. Wider global culture has the dimension of freedom of learning by using digital learning resources optimally such as correspondence examples, learning by using broadcasting devices such as radio and television, learning by using networking facilities such as LAN, WAN, intranet, internet and others [18].

Educational and learning organizing institutions are entities that have global cultural influence. This is marked using information and communication technology in learning activities and in finding learning resources. Information and communication technology has always been a topic of discussion and is also used as a tool for finding, processing, managing, displaying and delivering learning resources. This is the reason that the organization of education and learning will follow the global culture by implementing the development of information and communication technology in the field of education and learning.

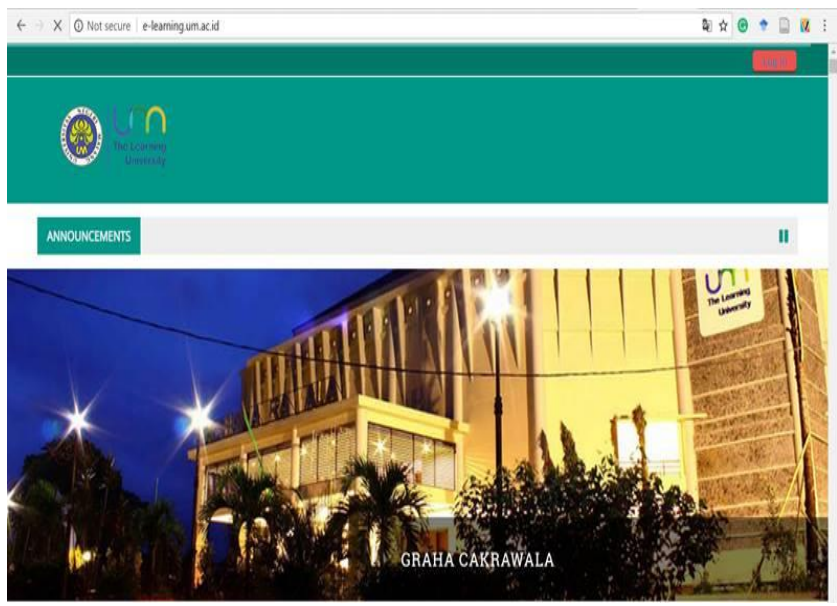

Fig. 4. Web Learning Management at the State Universitas of Malang

Educational and learning delivery institutions continuously strive to develop information and communication technology as a form of service. These efforts are demonstrated through the provision of various information and communication technology facilities in the form of providing network installations [19], Website installation[20], Provision of hardware [21], giving users access rights learning resources through certain pathways, and to support learning activities, especially the need for learning resources, in the environment 1 the organization of education and learning, both in planning and development, must strive to provide network facilities, access devices and the Internet that can reach the entire environment and provide education and learning as information and communication services as digital learning resources that can be utilized by lecturers as well as by prospective teachers. The paths used to serve our local, internet.

\section{SELECTION OF MEDIA}

The choice of teaching methods and sources of digital learning depends on the learning situation, students, subjects, educators and institutions [22]. Digital learning resources and methods must get attention to their intrinsic characteristics. Teaching requires changes in the form of content must be done through the most appropriate media - be it audio, audio-visual, face to face, electronic media, self-study packages etc. and the choice of media must be part of the planning stage of curriculum development.

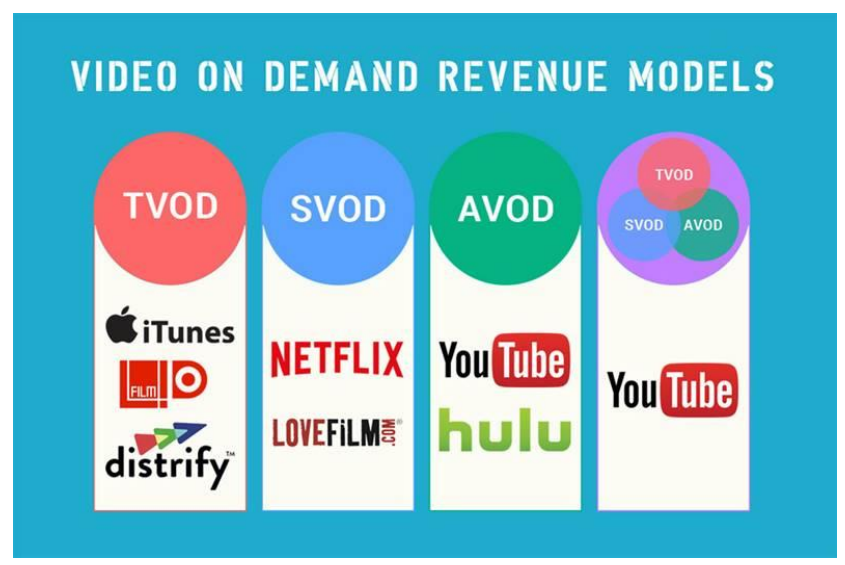

Fig. 5. Media Options ("SVOD, TVOD, AVOD," nd) [23]

Media selection is a crucial stage in the learning process used by educators and teachers. In an era where innovation in electronic media, now digital learning resources are present as a cause of confusion of choices for education practitioners, the selection of media and the factors that influence choice need to be fully understood if the right choice must be made.

Educational technology has seen a gradual but significant shift from the behavioral paradigm of the cognitive paradigm, to a constructivist perspective on learning design. This paradigm has explicit and implicit views of knowledge, students, and media. This is clearly demonstrated in the construction of different models of learning design and more specifically in media selection. Media learning needs to be selected and an approach is shared to share the general view of media selection as an important stage in the design of a learning event. A comprehensive manner how the user can choose digital learning resources through a series of questions designed to help for the group that rejects the media variant until the last choice is left for the appropriate digital learning program [24].

The heutagogy approach needs to be applied thoroughly to students of early childhood education, State University of Malang. The heutagogy approach is the use of digital learning resources developed by the students themselves, used as learning media. Digital learning resources developed by students themselves should not only be used in additional sessions in the learning and learning process. Users of digital learning resources developed by students themselves can explore the strengths and potential 
of digital learning resources so that the learning and learning processes are very valuable as in Figure 2 [12].

The use of digital learning resources in digital form must be a major factor in the quality of learning in the present era [13]. Besides that, the most important thing is the use of media and learning technology effectively and efficiently. Learning resources that are broadcast through digital learning resources are challenges and opportunities for educators and teachers. If effectiveness and efficiency are not ignored, then the fundamental laws that apply to the application of media and technology for learning and learning namely media and learning technology do not reduce development costs and do not improve learning outcomes [14].

\section{Heutagogy APPROACH Through MEDIA AND LEARNING RESOURCES}

Several studies have developed web applications with the heutagogy approach. Students of early childhood education at State University of Malang, in general, have used SIPEJAR LMS (figure 3) which was developed by the Education Technology team of State University of Malang. Early childhood education students need to utilize learning content.

In addition to LMS that has been used by students of early childhood education, MOOC has also been introduced by the Education Technology researchers from State University of Malang as shown in Figure 4. So that the vehicle for online-based learning is an effort of State University of Malang to offer more learning and online content, to a college student. Digital learning environment conditions, in accordance with several digital learning environment studies [25].

Online learning with an open nature like the MOOC (figure 4), offers a means to connect students of early childhood education at State University of Malang from 1) various locations, 2) backgrounds, and 3) cultures on different topics and interests. Various instructional studies based online shows that learners use online learning resource facilities in education and learning. Some researchers have presented new opportunities and new challenges in MOOC. But as a note, early childhood education students have not been given the opportunity in pedagogy to 1) choose content, 2) develop their learning resources by self and 3) utilizing the material developed together in learning is still not in the early childhood education department at the State University of Malang. So it is necessary to revitalize the heutagogy approach at LMS and MOOC State University of Malang with a heutagogy approach.

The heutagogy approach in LMS and MOOC for early childhood education students has a very important meaning. Web development is the most effective means of learning as a form of learning services at the State University of Malang. Increased use of effective online learning with the number of limited students at the State University of Malang has been developed [8].

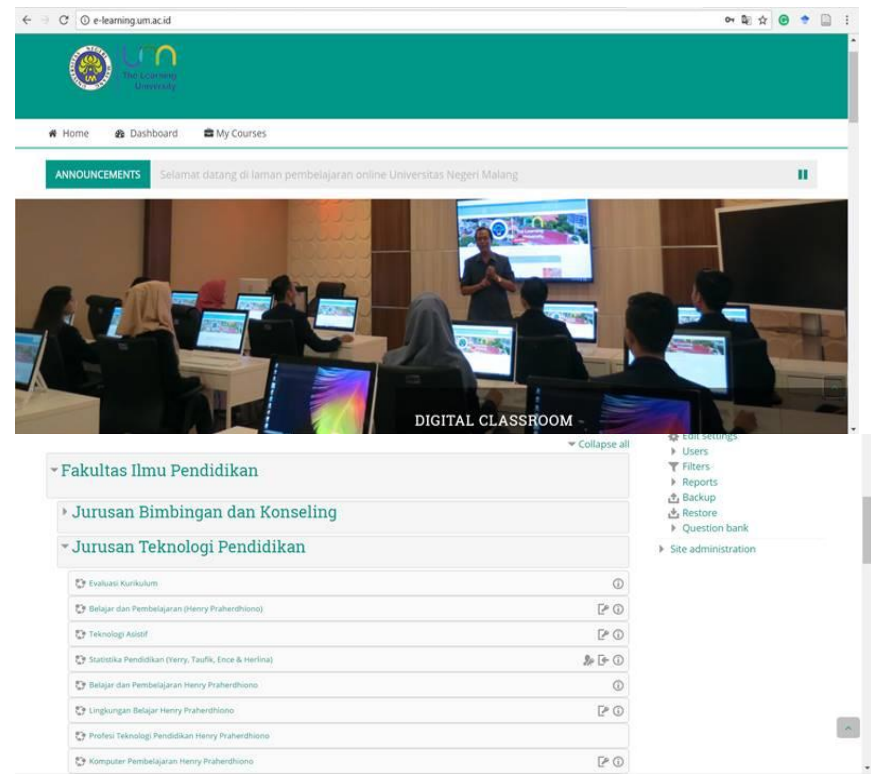

Fig. 6. SIPEJAR LMS of State Universitas of Malang

At the broader level of learning, web-based effective learning services have also been conducted. So that inside the broad meaning of MOOC is used only to meet all the needs of students. Research conducted in an effort to develop learning content with a heutagogy approach, namely pedagogy centered on students, by constructing learning resources independently.
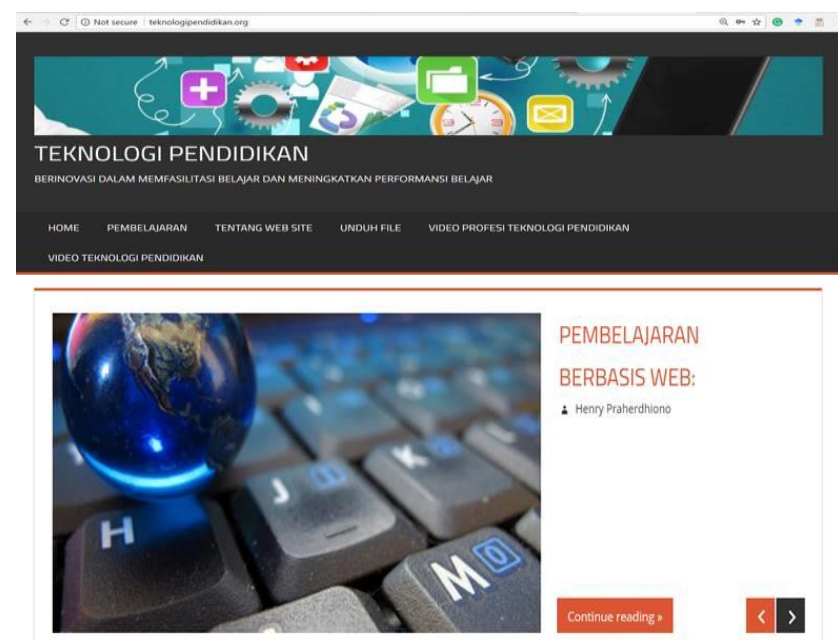

Fig. 7. MOOC of Educational Technology State University of Malang

\section{EDUCATORS AND TEACHERS IN DIGITAL LEARNING RESOURCES}

Good learning is provided by educators and instructors who are fluent in subject matter, information about the characteristics of their prospective teachers [26], able to provide knowledge in a meaningful, interesting and motivating way [12], guiding them towards a greater understanding of the subject matter which they choose and in knowledge, in general, are better prepared to function as part of the environmental study. How can an educator and teacher become good learners? Undoubtedly by opening 
communication channels [27], using all available and the most effective paths to reach prospective teachers [28].

Some excellent educators and teachers provide services using verbal communication channels, but most educators and teachers are indifferent to good communication. Here is the use of learning resources, media and technology help educators and teachers by making teaching tasks easier and building more useful teacher experiences. When dealing with high-tech media the personal disposition of educators to digital learning sources becomes important. This may involve the ability to change, explore new ways without prejudice, enthusiasm, to move from one learning model to another in a different subject, insight to display innovative thinking while maintaining a critical, rational approach to required learning outcomes, skills to adopt and develop personal styles that are compatible with certain media and strive for an optimal learning environment.

No technology can rival educators and instructors, if educators and instructors are experts in giving and receiving information. "Technology itself can teach, but without human elements, technology like a box of cables ..." [28]. Educators today have a marked fear of using digital learning resources and new strategies. The reason is simple, why bother to arrange equipment and borrow media - if someone can manage without them. After being educated with digital learning resources, many people tend to stay close to the media, approaching various theories, follow the path of the most resistance by adopting completely different methods like when they study.

Many educators and teachers have not yet convinced the media and technology places in education. New skills will be needed in building consensus and setting priorities that are proactive style replacing the typical reactive educators and instructors. Like every artist, an educator and teacher must acquire skills through formal training and education, and master skills through training. Educators must be knowledgeable and uncompromising in their efforts to provide the best for the situation the teacher candidates find themselves in. If educators have a phobia of certain digital learning resources, they are unlikely to use them properly. Questions about attitudes and feelings of educators and teachers are one of the most important factors that influence the success of any lesson. educators and instructors must have an open mind towards media use. Blatantly ignores the learning situation and the characteristics of prospective teachers, surely the source of digital learning will only lead to design and poor learning content.

There is a need to fully accept the possibilities and limitations of new technology. The gadget machine has the meaning that the use of media through which the subject of learning can be taught and that users cannot complete this task on their own. Only with media exposure for prospective teachers is not enough.

\section{CONCLUSION}

Education in the contemporary world requires that prospective teachers, early childhood education, change their traditional pedagogical practices, and become fish themselves are agents of learning, building heutagogy. Practical frameworks and models are needed in the heutagogy approach, namely how to utilize the best digital learning resources to learn and achieve learning outcomes from a multidimensional curriculum. 4 Such a framework serves as a strong intervention, aligning education professionals to transform traditional practices and promote a culture that focuses on learning. Here are some of the main issues that need to be considered:

Digital learning resources for learning and learning must be designed according to 2 types of curriculum knowledge content, that is, 1) these sources can not only be designed to support declarative and procedural learning, 2) digital learning resources for learning and learning can be designed to support development basic concepts that contribute to the importance of self-discipline and interdisciplinary knowledge.

Digital learning resources for learning and learning must be designed in a way that supports activities where knowledge is created and used, not just for the transfer of knowledge content. In this context, digital learning resources for learning and learning can function as tools that mediate the activities in which learning occurs, and shape learners' thinking and decision making. In other words, digital learning resources for learning and learning can practically be used in the representation of knowledge in activities where students are involved in (a) analytical processes to generalize and abstract concepts and ideas based on the ability of digital learning resources to learn, and (b ) whatever cognitive application residues appear in the process.

Digital learning resources for learning and learning must be designed to support activities that lead to the development of New Literacy. In this sense, digital learning resources for learning must not only present information in a comfortable way. Instead, this must require students to apply their literacy, such as visual, media and critical literacy to extract meaning. In addition, digital learning resources for learning and learning must be designed to support activities that facilitate the practice of New Literacy and development, such as those related to productive utilities of emerging technologies in developing digital essays.

Digital learning resources for learning should not only present information in a comfortable way. Instead, this must require students to apply their literacy, such as visual, media and critical literacy to extract meaning. In addition, digital learning resources for learning and learning must be designed to support activities that facilitate the practice of New Literacy and development, such as those related to productive utilities of emerging technologies in developing digital essays. Digital learning resources for learning should not only present information in a comfortable way. Instead, this must require students to apply their literacy, such as visual, media and critical literacy to extract meaning. In addition, digital learning resources for learning and learning must be designed to support activities that facilitate the practice of New Literacy and development, such as those 
related to productive utilities of emerging technologies in developing digital essays.

Digital learning resources for learning and learning can be designed to enable presentations to maximize the amount of content, often in small and temporal limited screen spaces through effective visual use, other multimodalities, and interactivity.

\section{REFERENCES}

[1] Hase, S., \& Kenyon, C. (2013). Self-determined learning: Heutagogy in action. A \& C Black.

[2] Phillips, DA, \& Shonkoff, JP (2000). From neurons to neighborhood: The science of early childhood development . National Academies Press.

[3] Currie, J. (2001). Early childhood education programs. Journal of Economic Perspectives , 15 (2), 213-238.

[4] Lewit, EM, \& Baker, LS (1995). School readiness. The Future of Children, 128-139.

[5] Boyer, EL, \& NJ), CF for the A. of T. (Princeton. (1991). Ready to learn: A mandate for the nation. The Carnegie Foundation for the Advancement of Teaching Princeton, NJ.

[6] Blackman, DA, Johnson, SJ, Buick, F., Faifua, DE, O'Donnell, M., \& Forsythe, M. (2016). The 70: 20: 10 models for learning and development: an effective model for capability development? (Vol. 2016, p. 10745). Presented at the Academy of Management Proceedings, Academy of Management.

[7] Baxter, J., Callaghan, G., \& McAvoy, J. (2018). Creativity \& Critique in Online Learning: Exploring and Examining Innovations in Online Pedagogy.

[8] Praherdhiono, H. (2014). Convenience of Learning Environment for Student Special Education With Cyberwellness Concept. Proceeding International Postgraduate University Kebangsaan Malaysia. SEAMOSEN

[9] Goodboy, AK, Bolkan, S., \& Baker, JP (2018). Instructors misbehavior lead to students' cognitive learning: testing the causal assumption. Communication Education, 1-22.

[10] Mayer, J., Borges, PV, \& Simske, SJ (2018). Introduction. In Fundamentals and Applications of Hardcopy Communication (pp. 1-5). Springer.

[11] Social Media Education - Build Social Marketing Channels That Make Sense. (2017, March 25). Retrieved July 31, 2018, from www.thetecexec.com.au/education/marketing-channels/

[12] Kormos, J., \& Csizer, K. (2014). The interaction of motivation, self-regulatory strategies, and autonomous learning behavior in different learner groups. Tesol Quarterly, 48 (2), 275-299.

[13] Kewal Ramani, A., Zhang, J., Wang, X., Rathbun, A., Corcoran, L., Diliberti, M., \& Zhang, J. (2018). Student Access to Digital Learning outside of the Classroom. NCES 2017-098. National Center for Education Statistics.

[14] Shadiev, R., Hwang, W.-Y., \& Liu, T.-Y. (2018). Investigating the effectiveness of a learning activity supported by a mobile multimedia learning system to enhance autonomous EFL learning in authentic contexts. Educational Technology Research and Development , 66 (4), 893-912.
[15] Wittich, CM, Agrawal, A., Cook, DA, Halvorsen, AJ, Mandrekar, JN, Chaudhry, S., Beckman, TJ(2017). E-learning in graduate medical education: survey of residency program directors. $B M C$ Medical Education, 17 (1), 114. https://doi.org/10.1186/s12909017-0953-9

[16] Aviram, A., Ronen, Y., Somekh, S., Winer, A., \& Sarid, A. (2008). Self-regulated personalized learning (srpl): Developing Classic Pedagogical Models. ELearning Papers , 9 (9), 1-17.

[17] Bonk, CJ, \& Graham, CR (2012). The handbook of blended learning: Global perspectives, local designs . John Wiley \& Sons.

[18] Aydin, CC, \& Tirkes, G. (2010). Open source learning management systems in e-learning and Moodle. In IEEE EDUCON $2010 \quad$ Conference (pp. 593600). https://doi.org/10.1109/EDUCON.2010. 5492522

[19] McKay, C., Keune, A., Peppler, K., Chang, S., Regalla, L., \& Initiative, ME (2015). A networked vision for sharing and documenting. Accessed May, 22 .

[20] Alexander, B. (2006). Web 2.0. A New Wave of Innovation for Teachings and Learning , 32-44.

[21] Tsai, C.-W., \& Shen, P.-D. (2015). Do Open Educational Resources and Cloud Classroom Really Improve Students' Learning? In Cloud Technology: Concepts, Methodologies, Tools, and Applications (pp. 2126-2134). Global IGI

[22] Praherdhiono, Henry, \& Pramono Adi, E. (2017). Constructing Learning Results as Learning Object Through Open Learning System. Atlantis Press. https://doi.org/10.2991/icet-17.2017.52

[23] SVOD, TVOD, AVOD: types of Video On Demand. (nd). Retrieved August 1, 2018, from http://dmarketing.tech/en/useful/447-svod-tvod-avod-types-ofvideo-on-demand

[24] Romiszowski, AJ (2016). Designing instructional systems: Decision making in course planning and curriculum design . Routledge.

[25] Bralić, A., \& Divjak, B. (2018). Use of moocs in traditional classroom: blended learning approach. European Journal of Open, Distance and E-Learning , 21 (1).

[26] Kim, HK, \& Bateman, B. (2007). Student characteristics and participation patterns in online discussion. In Society for Information Technology \& Teacher Education International Conference(Vol. 2007, pp. 2381-2387)

[27] Bagnol, B., Clarke, E., Li, M., Maulaga, W., Lumbwe, H., McConchie, R., ... Alders, RG (2016). transdisciplinary communication and knowledge project sharing experiences in Tanzania and Zambia through a One Health Lens. Frontiers in Public Health , 4 .

[28] Basitere, M., \& Ndeto Ivala, E. (2017) An Evaluation of the Effectiveness of the Use of Multimedia and Wiley plus WebBased Learning Enhancements in the Chemical Engineering Extended Physics Course Curriculum Program. Electronic Journal of E-Learning , 15 (2), 156-173.

[29] Murrow, ER (1967). In search of light: the broadcasts of Edward R. Murrow, 1938-1961 . Knopf. 